\title{
Using Effectiveness Index to support the Pubic Investment Evaluation \\ Practical study of Ministry of Sciences and Technology in Iraq
}

\author{
Anwar Mustafa Hasan \\ Wakwak77@yahoo.com \\ Ministry of Higher Education \&Scientific Research \\ Iraq/Baghdad
}

ABSTRACT: This Study seeks to demonstrate Using Effectiveness Index in the promotion of Pubic Investment Evaluation in the all sectors for the Ministry of Sciences and Technology in Iraq, the research has identified the problem by raising the following question: what role of Using Effectiveness Index to support the Pubic Projects Investment Evaluation?, and how the leaders' Ministry of Sciences and Technology in Iraq face challenges in making Investment, they must to create good Investment projects. The using of Effectiveness Index will relate to achieve organization objectives, it's important to quantify success in some way, to ensure evaluation results are objective, valid, reliable, and repeatable this research reviews the examines the effectiveness Index-aided Investment decisions makers. The aim: This research aiming for study and test the Effectiveness Index for evaluation results of Investment Decisions of the Iraq's public projection Ministry of Sciences and Technology, depending on explorative many interviews which had held with the projects owners of the Ministry for explanation the important of using Effectiveness Index for evaluation their projects. Evaluation is measuring success in a systematic and objective way. Evaluation focuses on whether the project was effective, achieved its objectives, and the outcomes had an impact for the project. For project outputs, evaluation might focus on whether the outputs are useful, meet user needs, and perform well. Displaying and analysis the research showed group of conclusions, the most important that Effectiveness Index plays a critical role in the Ministry that believe about the important of this Index is applied. Also recommendations, one of the most important, the Ministry of Sciences and Technology should give greater emphasis on the development the evaluation system for through using effectiveness index. To solve the problem of the study and meet its objectives, the researcher adopted the hypothesis: "Effectiveness Index supporting the Pubic Projects Investment of Ministry of Sciences and Technology in Iraq." 